\title{
In vitro transformation of MCF-10A cells by sera harvested from heifers two months post-Zeranol implantation
}

\author{
WEIPING YE ${ }^{1}$, PINGPING XU ${ }^{1}$, SAIYI ZHONG ${ }^{1}$, ROBERT JEN ${ }^{1}$, WALTER R. THRELFALL ${ }^{2}$, \\ CHRISTOPHER V. FRASURE ${ }^{3}$, ERIC FENG ${ }^{1}$, HONG LI $^{1}$, SHU-HONG LIN ${ }^{1}$, JIE-YU LIU ${ }^{1}$ and YOUNG C. LIN ${ }^{1,4}$ \\ ${ }^{1}$ Laboratory of Reproductive and Molecular Endocrinology, College of Veterinary Medicine, The Ohio State \\ University; Departments of ${ }^{2}$ Veterinary Clinical Sciences and ${ }^{3}$ Veterinary Biosciences, College of Veterinary \\ Medicine; ${ }^{4}$ The Ohio State University Comprehensive Cancer Center, Columbus, OH 43210, USA
}

Received October 19, 2010; Accepted December 3, 2010

DOI: $10.3892 /$ ijo.2011.941

\begin{abstract}
Among many risk factors of breast cancer, estrogens and non-estrogenic endocrine disruptors are considered to play critical roles in human breast carcinogenesis. Zeranol (Z) is a non-steroidal agent with potent estrogenic activity and has been widely used as an FDA approved beef growth promoter in the US. Recently, concerns have been raised about the potential adverse health risk by consumption of products containing biologically active $\mathrm{Z}$ and its metabolites. By utilizing cell proliferation assay, soft agar assay, quantitative real-time PCR and Western blotting analysis, we examined the potentially tumorigenic activity of bio-active $\mathrm{Z}$ containing sera harvested from heifers two months post Z-implantation and the underlying mechanisms. Our results showed that the growth of MCF-10A exposed to $0.2,1$ and 5\% Z-containing serum (ZS) treatment for 3 weeks was 1.3, 1.75 and 1.8-fold faster compared to that of the control sera. After further investigation, we found that ZS increased cyclin D1 and decreased p53 expression at the mRNA and protein levels in MCF-10A compared to the controls. More importantly, treatment of $1 \% \mathrm{Z}$-containing sera for 21 days stimulated MCF-10A cells anchorage-independent colony formation in soft agar which illustrates its capability of inducing human normal breast epithelial cell neoplastic transformation. Our experimental results suggest that longterm exposure of low levels of $\mathrm{Z}$ and its metabolites contained in beef products might be a potential risk factor in human breast cancer initiation and development.
\end{abstract}

\section{Introduction}

Breast cancer is one of the most common malignances among women in the US. Despite many advances in breast cancer

Correspondence to: Dr Young C. Lin, Laboratory of Reproductive and Molecular Endocrinology, College of Veterinary Medicine, The Ohio State University, Columbus, OH 43210, USA

E-mail:1in.15@osu.edu

Key words: breast cancer, growth promoter, Zeranol, Zeranol containing serum, transformation, $\mathrm{p} 53$, cyclin D1 detection and treatment, we are still no closer to eradicating this disease because it is more complex than we previously thought. In the United States, more than one-fourth of cancer patients were breast cancer patients in 2009 and breast cancer ranks as the second leading cause of cancer-related deaths (1). According to clinical cancer statistics, it was estimated that 182,500 new cases arose each year, and about 40,500 died from breast cancer in the US in 2009 (1). Epidemiological studies suggest that there are many risk factors associated with breast cancer such as dietary fat and environmental estrogenic endocrine disruptors. The relationship between dietary fat intake and risk of breast cancer has been studied in ecological, etiologic, and intervention research and animal experimentation. Unfortunately, the results are still not consistent.

Zearalenone, a stable natural product that mimics estrogen activity, is a carcinogen, hazardous to human health (2). Researchers found that Zearalenone may represent a growth promoter in exposed patients, and there is a possible relationship between environmental mycoestrogen exposure and the development of central precocious puberty (3). Zeranol, produced from Zearalenone, is a non-estrogenic anabolic growth promoter and is widely used in the US beef industry to accelerate weight gain, to improve feed conversion efficacy, quality of carcass, and to increase the lean meat-to-fat ratio (4). Previous investigation showed that using $\mathrm{Z}$ as a growth promoter was relatively safe for human consumption and subsequently approved by the FDA based on its toxicity information. In 1996 the Europe Union (EU) banned the imports of meat from animals with any growth promoter implantation from the US due to potential adverse health concerns. This resulted in the US government taking legal action to the World Trade Organization (WTO) to challenge their ban. Although the dispute was resolved by WTO in favor of the US appeal, the EU continued to ban even if the US government imposed trade sanctions consisting of a $100 \%$ increase on tariffs of selected products imported from EU member countries. It is urgent to provide additional evidence to clarify whether consumption of the beef products with $\mathrm{Z}$ and its residues is safe or not. This critical issue is related to not only human health, but also economics as well as politics.

Recent research has found that $\mathrm{Z}$ might not be as safe as the FDA claimed before. Both Zearalenone and Zeranol can 
bind to the active site of human estrogen receptor $\alpha(\mathrm{ER} \alpha)$ and $E R \beta$ in a similar manner to $17 \beta$-estradiol $\left(E_{2}\right)(5)$. As a food contaminant, the intake of $\mathrm{Z}$ is very hard to avoid (2). Researchers found that at low concentrations, it can increase ER $\alpha$-positive cell growth, but at high concentrations $\mathrm{Z}$ can reduce growth of both ER $\alpha$-positive and -negative cell lines (6). Our previous data showed that pure $\mathrm{Z}$ was able to transform normal human breast epithelial cells and to increase human breast cell growth in a dose-dependent manner (5). Our data also showed that $\mathrm{Z}$ can down-regulate the expression of estrogenregulated human breast cancer candidate suppressor gene, protein tyrosine phosphatase $\gamma(\mathrm{PTP} \gamma)(7)$. We also have evidence showing that leptin induces human breast cancer epithelial cell sensitivity to Z . Leptin is a key player in obesity (8). Swan and his colleagues claimed that the number of beef meals consumed by the mother during their pregnancy was significantly and inversely related to their son's sperm concentration (9). Higher red meat intake in adolescence may increase the risk of premenopausal breast cancer (10). An investigation on occupational exposure to $\mathrm{Z}$ found that an excess of breast symptoms such as sharp pain, tingling, burning, aching, or irritation of the breasts was reported among male and female workers exposed to $\mathrm{Z}$; however, the numbers were small, and no significant difference was found compared to the unexposed group. Interestingly, the same investigation found that at least two boys had breast enlargement and discomfort, and this was directly associated with their exposure to $\mathrm{Z}$ because their parents wore work clothes at home. The symptoms in these two boys abated after their parents exposure to $\mathrm{Z}$ was controlled by the plant (11). Our previous experimental results show that the growth of pre-adipocytes derived from beef heifers implanted with 60 days of Zeranol was about 12-fold faster than that from the control beef heifer. The response of $\mathrm{Z}$-implanted pre-adipocytes to the treatment of $\mathrm{Z}$ and $\mathrm{E}_{2}$ was more sensitive than that of the pre-adipocytes derived from the control beef heifer (12). It is very important to understand whether biological samples harvested from beef heifers with $\mathrm{Z}$ implantation have any adverse health effects on the human breast. We found that Z-containing sera (ZS) harvested from beef heifers 60 -day post-Z-Implantation $(72 \mathrm{mg}$ ) were more potent in stimulating MCF-7 proliferation than those from the control beef heifers and such increase in proliferation might be due to up-regulating cyclin D1 and down-regulating p53 at the mRNA and protein levels in the cells.

In order to explore the possibility of tumorigenic function of ZS on human breast tumorigenesis, cell counting, real-time PCR, Western blot analysis and soft agar assay were used to investigate the effects of ZS on human normal breast epithelial cell line, MCF-10A, and the mechanisms that might be involved in. Our experimental results suggest that Z-implanted beef poses an adverse health risk. The investigation of the mechanisms of the ZS induced proliferation of MCF-10A cells was conducted by cell proliferation assay, RT-PCR, and Western blotting. Soft agar for colony formation was also performed.

\section{Materials and methods}

Animal treatment and blood sampling. The animal experiments were approved by The Ohio State University Research Foundation and carried out in accordance with their rules on animal care and experimentation. Ralgr ${ }^{\circledR}$ Magnum (RM, commercial $\mathrm{Z}$ pellet) was purchased from Merck-ScheringPlough Corp, Rahway, NJ, USA, in the form of cartridges, each containing six $12 \mathrm{mg} \mathrm{Z}$. Twenty cross-bred Angus beef heifers (about one year old) purchased from the Department of Animal Science were randomly divided into two groups according to their initial body weights. The animal treatment was described in our previous publication (12). Serum obtained from both the Z-implanted beef heifer at 60 days post $\mathrm{Z}$ implantation (ZS) and the control beef heifer at the same time (NZS) was sterilized by $50 \mathrm{ml}$ conical filter tube and stored at $-20^{\circ} \mathrm{C}$.

Cell culture. MCF-10A cells were purchased from the American Type Culture Collection (ATCC, Manassas, VA, USA) and cultured in phenol red-free low calcium Dulbecco's modified Eagle's medium and Ham's F12 medium (1:1) (DMEM/F12) $\left(0.04 \mathrm{mM} \mathrm{CaCl}_{2}\right)$ containing $10 \%$ Dextrancoated charcoal (DCC) stripped fetal bovine serum (FBS) (Atlanta Biologicals, Norcross, GA, USA) and antibioticantimycotic (100 unit/ml penicillin $\mathrm{G}$ sodium, $100 \mu \mathrm{g} / \mathrm{ml}$ streptomycin sulfate and $0.25 \mu \mathrm{g} / \mathrm{ml}$ amphotericin B) (Invitrogen, Carlsbad, CA, USA) in a T75 culture flask in a humidified incubator $\left(5 \% \mathrm{CO}_{2}, 95 \%\right.$ air, $\left.37^{\circ} \mathrm{C}\right)$. When the cells grew to $85-90 \%$ confluence, cells were subcultured into T75 culture flasks at a ratio of 1 flask to 3 flasks as described above. Cells were dissociated using $3 \mathrm{ml}$ of $0.25 \%$ trypsin-5.3 mM EDTA (Invitrogen) in phosphate buffered saline (PBS) for $3 \mathrm{~min}$ at $37^{\circ} \mathrm{C}$. The trypsinization was stopped by the addition of $10 \mathrm{ml}$ of culture medium with $10 \%$ FBS (Invitrogen). After centrifugation, the dissociated cells were resuspended in the culture medium with $10 \%$ low calcium FBS and subcultured into T75 culture flasks at a ratio of 1 flask to 3 flasks.

Cell proliferation determination. Approximately $1 \times 10^{5}$ MCF-10A cells were seeded in a T75 flask in $10 \mathrm{ml}$ of low calcium DMEM/F12 medium supplemented with 10\% DCC stripped FBS and cultured overnight. Cells were then treated with the same medium but containing $0.2,1$ and $5 \%$ of $\mathrm{ZS}$ or NZS. MCF-10A cells were continuously cultured 21 days. Medium was replaced every two days. Pictures were taken using a Nikon digital camera (digital sight DS-Fi1, Nikon Corporation, Japan) connected with Nikon Diaphot inverted microscope and an IBM computer installed with a photodocumentation software (Nis-Elments, version 2.33). Once the cells grew nearly confluent, all the cells in the flask were collected, and cell numbers were counted using the trypan blue exclusion method. The same number of MCF-10A cells with different treatment were separately reseeded in different T75 flasks and continuously treated as previously described above until 21 days. One part of the cell from each treatment group were collected and frozen in liquid nitrogen tank. The rest was used for soft agar assay.

RNA isolation, cDNA synthesis and real-time PCR analysis. After a 10-day culture, total RNA was isolated from MCF-10A in different treatment groups using TRIzol ${ }^{\circledR}$ Reagent (Invitrogen, Carlsbad, CA, USA) according to the manufacturer's instructions. After RNA concentration was measured by ND-1000 spectrophotometer (NanoDrop Technologies, Inc., Wilmington, DE, 
USA). RNA ( $1 \mu \mathrm{g})$ from cultured cells was reverse transcribed with $200 \mathrm{U}$ M-MLV Reverse Transcriptase (Invitrogen) at $37^{\circ} \mathrm{C}$ for $50 \mathrm{~min}$ and then $70^{\circ} \mathrm{C}$ for $15 \mathrm{~min}$ in the presence of $1 \mu 110 \mathrm{mM}$ dNTP (10 mM each dATP, dGTP, dCTP, and dTTP at neutral pH) (Invitrogen,), $1 \mu 150 \mu \mathrm{M}$ Random hexamer (Amersham, Piscataway, NJ, USA), $10 \mu 1$ 5X First Strand buffer, $5 \mu 10.1 \mathrm{M}$ DTT and $1 \mu 1$ RNase Inhibitor (Invitrogen) in a total volume of $50 \mu \mathrm{l}$ in a gradient mastercycle (Eppendorf ${ }^{\circledR}$, Westbury, NY, USA). Real-time PCR conditions were optimized for every primer pair and performed in Stratagene Mx3005p (Agilent Technologies, Cedar Creek, TX, USA). Two microliters of the newly synthesized cDNA was used as a template for the reaction in a total volume of $20 \mu 1$ reactants which included $10 \mu 1$ of $2 X$ real-time PCR master mix (Applied Biosystems, Woolston, Warrington, UK), $3 \mu \mathrm{l}$ ultra-pure water, and $5 \mu \mathrm{l}$ of primer mixer. The reactants were first incubated at $95^{\circ} \mathrm{C}$ for $10 \mathrm{~min}$, and then 40 cycles of amplification were taken place with each cycle consisting of denaturing at $95^{\circ} \mathrm{C}$ for $30 \mathrm{sec}$, annealing at $55^{\circ} \mathrm{C}$ for $1 \mathrm{~min}$, and elongating at $72^{\circ} \mathrm{C}$ for $1 \mathrm{~min}$. A dissociation curve was also made at the completion of PCR in order to ensure that the reaction produced correct products as anticipated. The primer sequences for cyclin D1 were 5'-TTGGTTA CAGTAGCGTAG-3' (sense) and 5'-TTATAGTAGCGTATCGT AGG-3' (antisense). The primer sequences for $\mathrm{p} 53$ were 5'-GACAATGGCAGC ATCTAC-3' (sense) and 5'-GAAGGTGTAATCAGTCTCC-3' (antisense). The primer sequences for 36B4 were 5'-ACATG CTCAACATCTCCC-3' (sense) and 5'-GCGGCACTTCT CCTGCTCC-3' (antisense). The results of the relative mRNA expression (cyclin D1 and p53 to 36B4) in MCF-10A cells were analyzed by using $\Delta \Delta \mathrm{Ct}$ method (13).

Western blot assay. After 10 days of treatment, MCF-10A cells from each treatment group were lysed by adding $0.5 \mathrm{ml}$ of M-PER ${ }^{\mathrm{TM}}$ Mammalian Protein Extraction Reagent (Thermo, Rockford, IL, USA) and $5 \mu 1100 \mathrm{X}$ protease inhibitor (Thermo Scientific, Waltham, MA, USA). The cell lysate was collected into a $1.5 \mathrm{ml}$ microcentrifuge tube and samples were centrifuged at $27,000 \times \mathrm{g}$ at $4^{\circ} \mathrm{C}$ for $10 \mathrm{~min}$ to pellet the cell debris. Finally, the supernatant layer containing proteins was transferred to a clean tube for analysis. The concentration of total protein was determined by using Micro $\mathrm{BCA}^{\mathrm{TM}}$ Protein Assay (Pierce Biotechnology Inc., Rockford, IL, USA) according to the manufacturer's instructions. Protein $(50 \mu \mathrm{g})$ from each sample was mixed with an appropriate volume of $3 \mathrm{X}$ Laemmli sample buffer (62.5 mM Tris-HCl, pH 6.8, 2\% SDS, 25\% glycerol, $0.01 \%$ bromophenol blue) (Bio-Rad Laboratories, Hercules, CA, USA) and was then denatured at $100^{\circ} \mathrm{C}$ for $5 \mathrm{~min}$. Mixtures were loaded onto $10 \%$ Tris- $\mathrm{HCl}$ gel for SDS-PAGE (Bio-Rad Laboratories) and electrophorsed at $200 \mathrm{~V}$ for about $1 \mathrm{~h}$ in $1 \mathrm{X}$ Tris/Glycine/SDS buffer ( $25 \mathrm{mM}$ Tris- $\mathrm{HCl}, 250 \mathrm{mM}$ glycine, $0.1 \%$ SDS, $\mathrm{pH}$ 8.3). The separated proteins were then transferred to a piece of polyvinylidene fluoride (PVDF) membrane (Bio-Rad Laboratories) under current density at $0.08 \mathrm{~mA} / \mathrm{cm}^{2}$ for approximate time according to the manufacturer's instruction. After the protein was transferred, the membrane was immediately soaked in $100 \%$ methanol for $10 \mathrm{sec}$ and then placed on a piece of filter paper until it was dry. The membrane was then blocked in PBST (PBS $+0.1 \%$ Tween-20) solution containing $10 \%$ non-fat milk and incubated at $4^{\circ} \mathrm{C}$ overnight. For immunoblotting, we used the following primary antibodies: rabbit polyclonal antibodies against cyclin D1 and p53 (Cell Signaling Technology, Danvers, MA, USA), goat polyclonal antibody against $\beta$-actin (Santa Cruz Biotechnology, Santa Cruz, CA, USA). The secondary antibody for cyclin D1 and p53 detection was ECL ${ }^{\mathrm{TM}}$ anti-rabbit IgG linked to horseradish peroxidase (HRP) (Amersham Biosciences, Buckinghamshire, UK ) and a donkey anti-goat IgG HRP for $\beta$-actin detection (Santa Cruz Biotechnology). Images were taken using FujiFilm LAS-3000 image system (FujiFilm Medical Systems USA, Inc.).

Soft agar assay for colony formation. MCF-10A collected at the end of 21 days treatment with $1 \%$ of ZS and NZS in culture medium were cultured in 6-well plates. First layer was covered with an agar layer (phenol red-free low calcium DMEM/F12 with $0.5 \%$ agar and $10 \%$ FBS). The middle layer contained 8,000 cells in phenol red-free low-calcium DMEM/ F12 with $0.35 \%$ agar and $10 \%$ FBS. The top layer, consisting of medium, was added to prevent drying of the agar in the plates. The plates were incubated for 15 days. Pictures were taken under a phase contrast microscope at regular time.

Statistical analysis. The results for the cell counting are presented as mean \pm standard error (SE) for 3 replicate culture flasks. Analysis was performed by using Minitab 15 (Minitab Inc., State College PA, USA). Statistical difference was determined by using two-sample t-test analyses for independent samples. The statistical differences between the ratio of cyclin D1, p53 and 36B4 mRNA expression in MCF-10A cells were determined by using one-way ANOVA for each independent treatment group. Statistical significance was set at $\mathrm{p}<0.05$.

\section{Results}

ZS is more potent in stimulating MCF-10A proliferation as compared to NZS. Our previous investigation found that pre-adipocytes derived from the beef heifer with two months $\mathrm{Z}$ implantation grew about 12-fold faster than that from the control beef heifer (12). To explore whether ZS stimulates human normal breast epithelial cell line, MCF-10A growth, we treated MCF-10A cells with different concentrations of ZS as well as NZS in the culture medium. The results are shown in Fig. 1A and B. After 48 and $120 \mathrm{~h}$ treatment, the number of cells treated with $1 \% \mathrm{ZS}$ are larger than that treated with just control medium or containing 1\% NZS (Fig. 1A). The growth of MCF-10A cells exposed to $0.2,1$, and $5 \% \mathrm{ZS}$ for 10 days was $1.48,2.08$ and 2.11 -fold faster than that exposed to the same concentrations of NZS (Fig. 1B). At the same concentration, the growth of MCF-10A exposed to ZS treatment was faster than that of NS treatment.

ZS up-regulates cyclin D1 and down-regulates p53 mRNA expression in MCF-10A cell. Our previous investigation found that ZS regulated the mRNA expression of cyclin D1, p53, p21 in MCF-7 cells (14). In order to explore if ZS has a similar regulatory effect on MCF-10A, we continuously treated MCF-10A with different concentrations of NZS and ZS for 10 days and then isolated total RNA. After cDNA was synthesized using $1 \mu \mathrm{g}$ RNA as a template, real-time PCR analysis 
A
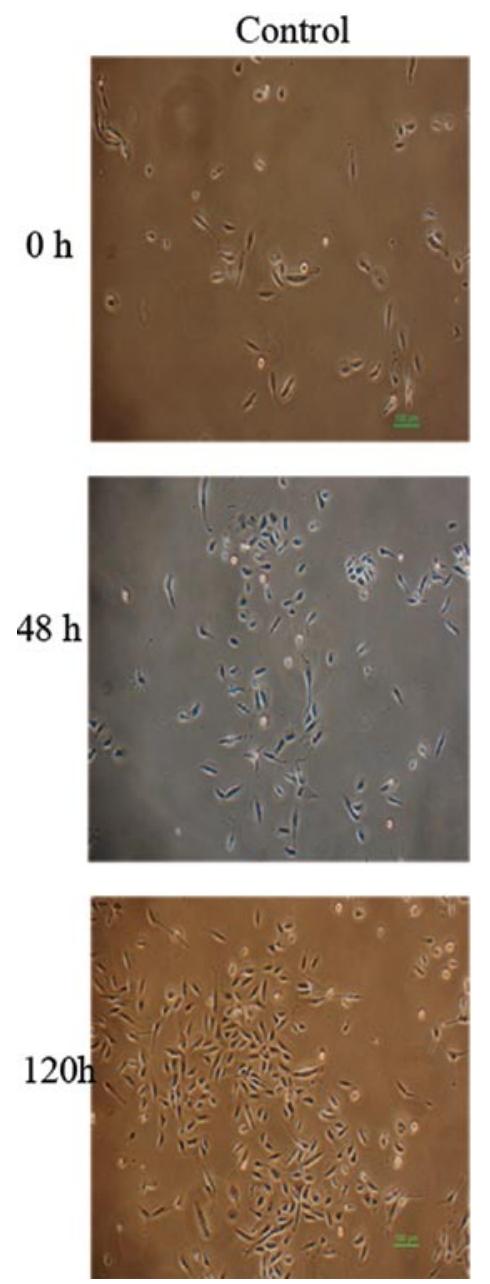
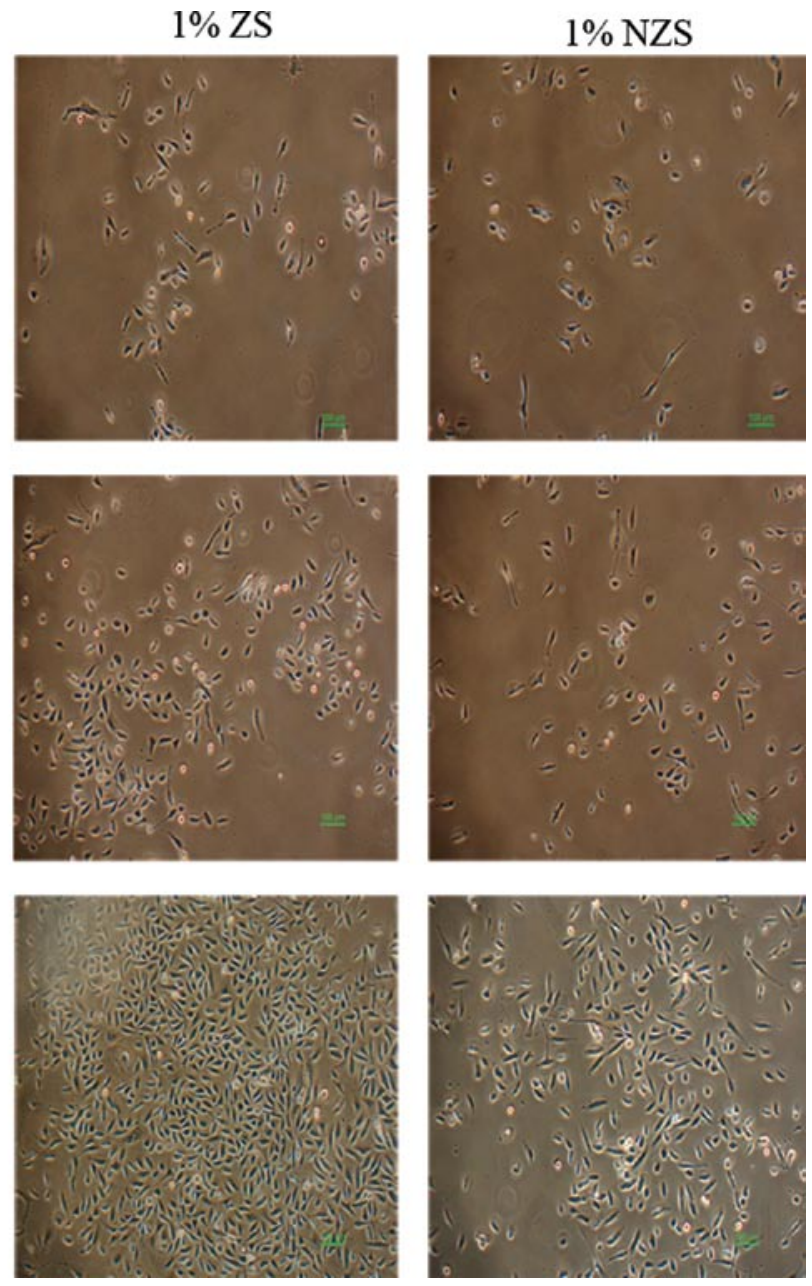

B

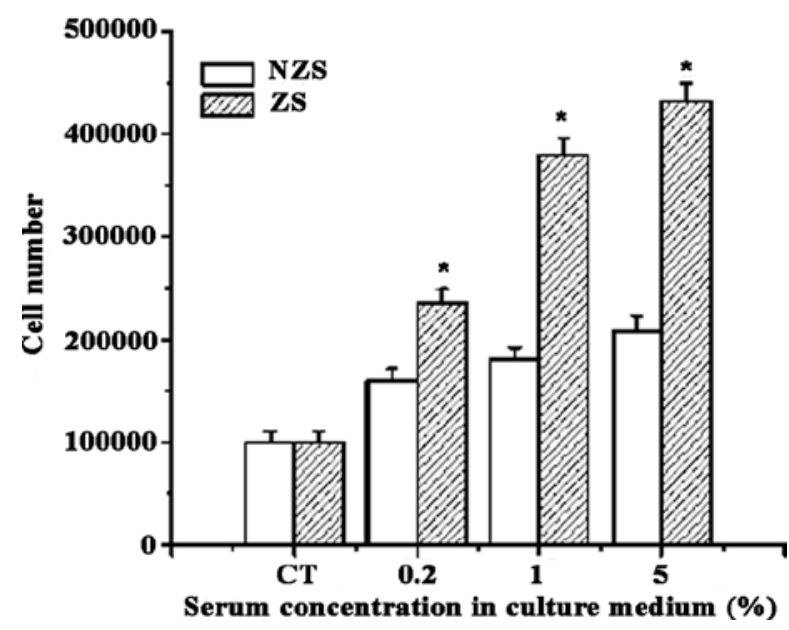

Figure 1. Comparison of the growth of MCF-10A cells after treated with control medium, media containing ZS or NZS. (A) Illustration of MCF-10A cell number after treatment of control medium, media containing $1 \% \mathrm{ZS}$ or NZS for 48 and $120 \mathrm{~h}$ (10x10 magnification). Approximately $1 \times 10^{5}$ viable MCF-10A cells were seeded in T75 flasks and then treated with control medium, media containing $1 \%$ ZS or NZS for 48 and $120 \mathrm{~h}$. Pictures were taken as described in 'Materials and methods'. (B). MCF-10A cell proliferation determined by trypan blue exclusion method after MCF-10A cell treated with culture media containing NZS and ZS at $0.2,1$ and $5 \%$ for 7 days. Each T75 flask was seeded $1 \times 10^{5}$ MCF-10A cells and then separately treated with different concentrations of NZS or ZS until cells were confluent. Cell number was counted as described in 'Materials and methods'. Each bar represents the mean \pm SD for 3 replicate flasks. The asterisk indicates the statistically significant difference between two bars $(\mathrm{p}<0.05)$. was performed to amplify cyclin D1, p53 and 36B4 genes. The results are shown in Fig. 2A and B. The expression of cyclin D1 were significantly increased after a 10-day treatment of $0.2,1$ and $5 \% \mathrm{ZS}$, while the expression of cyclin D1 mRNA in MCF-10A treated with $0.2,1$ and $5 \%$ NZS did not change greatly (Fig. 2A). Regarding p53 gene expression, $0.2,1$ and $5 \% \mathrm{ZS}$ treatment down-regulated $553 \mathrm{mRNA}$ expression after ten day treatment (Fig. 2B) to $1.74,26$, and $52 \%$ in MCF-10A as compared to the control group. Different concentrations of NZS treatment did not alter the expression of p53 mRNA in cells significantly as compared to the control; however, NZS-D60 has no effect on cyclin D1 expression, compared to control group.

ZS increases cyclin DI and down-regulated the p53 protein expression in MCF-10A cells. Further investigation using Western blot analysis, we found that treatment of $0.2,1$ and $5 \%$ of ZS increased cyclin D1 protein expression in MCF-10A to $2.4,11.7$ and $13.3 \%$, compared to control group. NZ treatment did not significantly change cyclin D1 protein expression in MCF-10A. On the contrary, the expression of $\mathrm{p} 53$ protein was up-regulated dose-dependently in MCF-10A treated with different concentrations of ZS. Similarly, NZ treatment did not change expression significantly in MCF-10A cells (Fig. 3).

Effects of ZS and NZ treatment on anchorage-independent growth of MCF-10A cells. A previous investigation suggested 


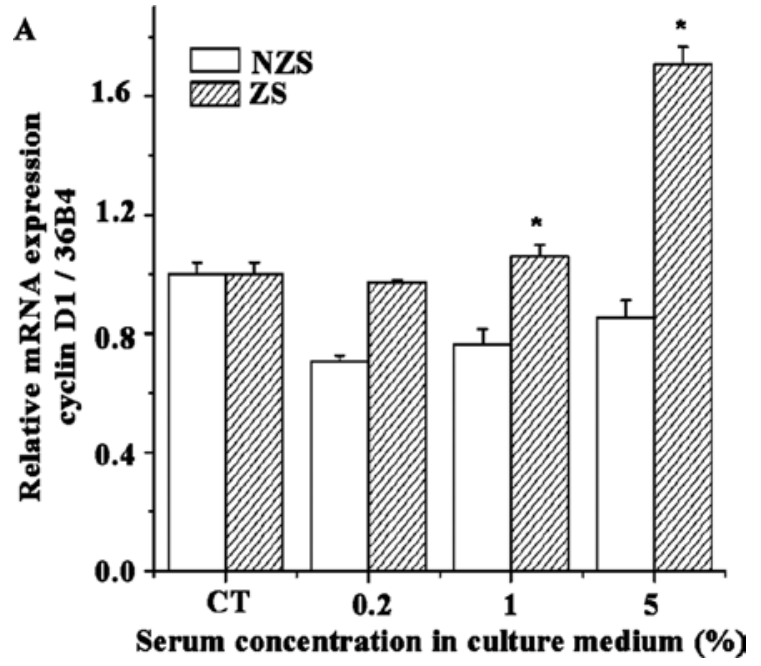

B

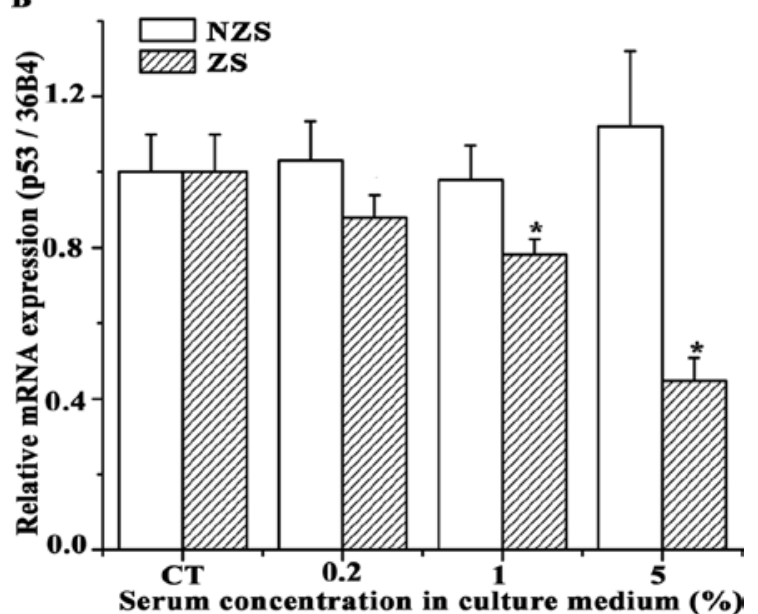

Figure 2. Effects of NZS and ZS on the expression of cyclin D1 and p53 mRNA in MCF-10A after a 10-day treatment. Total RNA was isolated from MCF-10 A cells treated with different concentration of NZS, ZS or vehicle control for 10 days and real-time PCR was performed. The mRNA ratios of cyclin D1 to 36B4 (A) or p53 to 36B4 (B) were calculated by using $\Delta \Delta \mathrm{C}$ method. Each bar represents the mean \pm SD for 3 replicate flasks. The asterisk indicates the statistically significant difference as compared to the control $(\mathrm{p}<0.05)$. The results show that the expression of cyclin D1 is up-regulated and p53 mRNA decreased in MCF-10A cells by the treatment of ZS compared to that of NZS treatment.

it was an indicator of neoplastic transformation that human normal breast epithelial cells grow anchorage independently and form colony in soft agar (15). Our laboratory found that both $\mathrm{Z}$ and $\mathrm{E}_{2}$ can induce MCF-10A cell neoplastic transformation with similar potency after a long-term exposure (5). In the current study, using the same method as described in previous literature, we investigated if $\mathrm{ZS}$ possesses similar capabilities. After 21 days of treatment with $1 \%$ ZS, MCF-10A cells undergo anchorage-independent growth and then form colonies in $0.35 \%$ soft agar, while cells treated with 21 days of NZS and control medium did not grow or form any colony in the soft agar (Fig. 4). It suggests that certain biological active components exist in ZS which facilitate MCF-10A cell neoplastic transformation thus resulting in anchorageindependent growth and colony formation (Fig. 4).

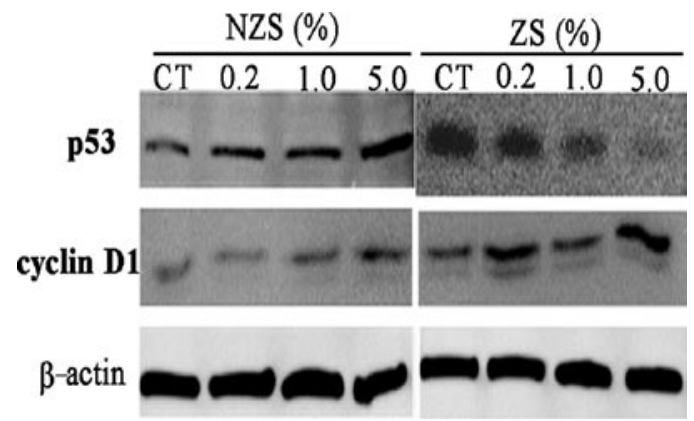

Figure 3. Effects of NZS and ZS treatment on cyclin D1 and p53 protein expressions in MCF-10A cells. After 10 days of treatment, protein was extracted from each treatment group as described in 'Materials and methods' section. Western blot analysis was performed to detect the protein expression of cyclin D1 and p53 in MCF-10A treated with different concentrations of ZS or NZS for 10 days.

\section{Discussion}

Numerous evidence shows that white American women have been found to experience higher all-stages rates of breast cancer incidence than African-American, Hispanic-Latino, American Indian, and Asian women (16,17). Strong scientific support has been accumulating for the fact that immigrants undergo changes in breast cancer risk after their relocation (18-20). Female Asian immigrants in the US express similar incidence of breast cancer as American women after 1 to 2 generations (21). This suggests that breast cancer is influenced by modifiable lifestyle or environmental factors. Researchers pointed out the importance of diet in breast cancer development. In a study involving omnivorous and vegetarian women residing in Boston, the omnivores eating a Western diet had higher urinary and lower fecal estrogen levels than vegetarians. Furthermore, it was found that there was an inverse correlation between plasma-estrogen levels and fecal-estrogen excretion (22). Estrogen has been confirmed to be a carcinogen for breast cancer. Higher levels of estrogens in the plasma and urine are thought to be associated with human breast cancer (23-26). The relationship between higher levels of estrogens and fat diet has been explored by several researchers; however, epidemiological studies have shown conflicting results regarding an association of dietary fat with breast cancer. Recently, a prospective study on postmenopausal US women found that dietary fat intake was weakly but significantly associated with the risk of invasive breast cancer, whereas intakes of saturated, monounsaturated, and polyunsaturated fat each were significantly related to breast cancer risk (27). It is well-known that aromatase plays an important role in breast cancer development because it converts androgen to estrogen, resulting in higher concentrations of estrogen $(28,29)$.

Our previous results demonstrated that the pre-adipocytes derived from the beef heifers implanted 2 months with $\mathrm{Z}$ grew about 12-fold faster than that from the control beef heifers, and they are more sensitive to estrogen as well as $\mathrm{Z}$ as compared to the pre-adipocytes derived from the control beef heifers (12). Temporally, we do not know whether long-term consumption of beef products containing low level residues of $\mathrm{Z}$ or its biologically active metabolites will have similar effects on humans. Further investigation is needed urgently. 

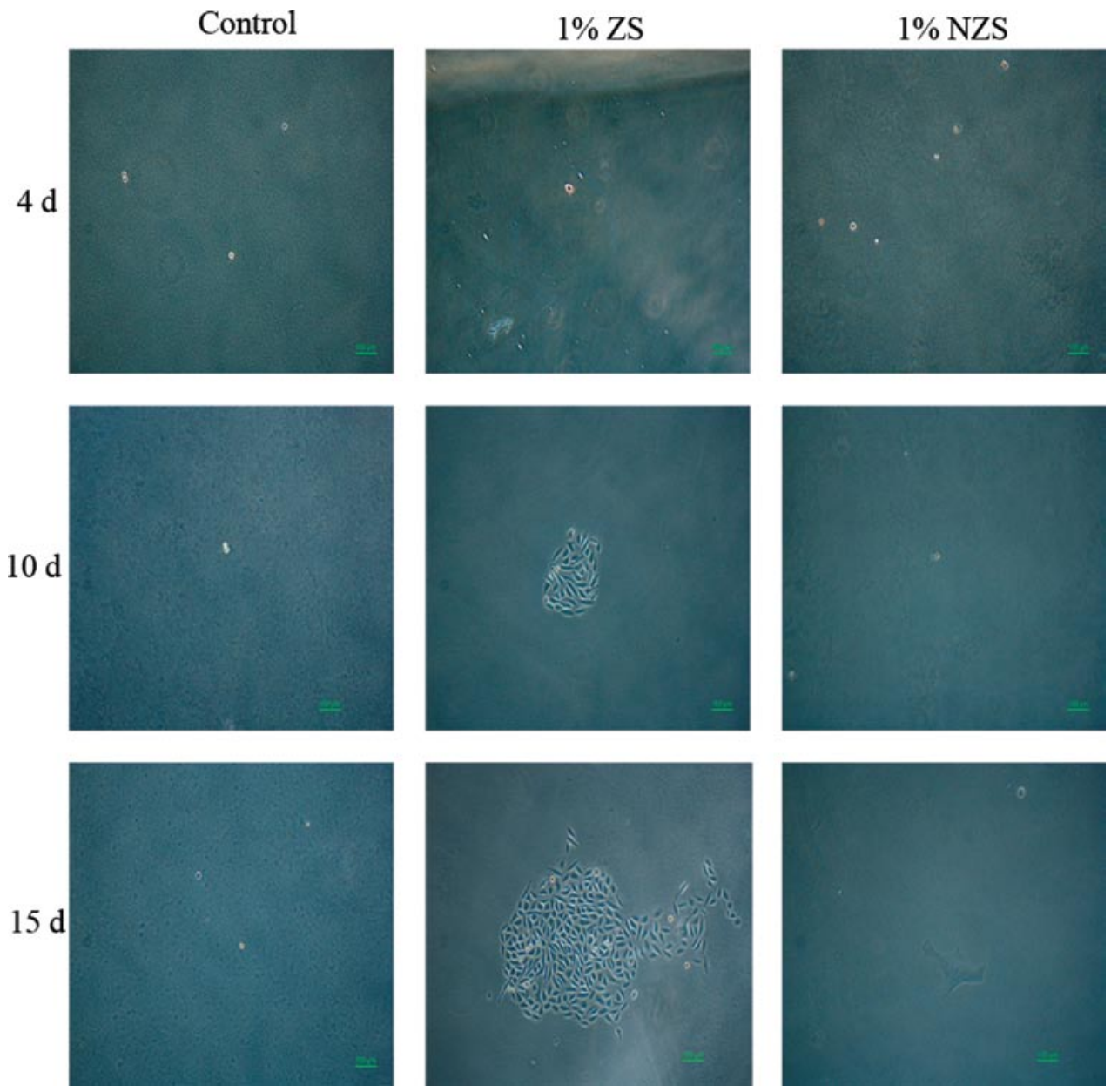

Figure 4. Effects of $1 \%$ ZS and NZS on anchorage-independent growth of MCF-10A cells in soft agar. MCF-10A cells were cultured in 6-well plates first covered with an agar layer; the middle layer contained 8,000 cells (MCF-10A cells treated with 1\% ZS, NZS or control medium for 21 days); the top layer is covered by low calcium DMEM/F12 medium to prevent drying of the agarose gels during incubation. Pictures were taken under a phase contrast microscope at different time points (10x10 magnification).

P53 is a tumor suppressor gene which plays a crucial role in regulating cell growth following exposure to various stress stimuli. It induces growth arrest or programmed cell death (apoptosis), and it also plays an important role in the control of cell cycle checkpoint. p53 is the most frequently mutated gene in human cancers and $15-60 \%$ of breast cancers contain p53 mutations (30). Loss of p53 occurs in approximately $80 \%$ in colorectal tumors (31). Consequently, its function has been extensively studied. It was reported that tumors cells with mutant p53 protein might be associated with poor prognosis (29).

The tumor suppressor $\mathrm{p} 53$ can regulate both cell proliferation and apoptosis. An imbalance between them will result in a rapid increase in cell number, the most prominent characteristic of tumors. Normal breast epithelial cells induce p53-dependent apoptosis and p53-independent cell cycle arrest of breast cancer cells (31). For premenopausal women, p53 mutations in breast tumors were associated with alcohol consumption in the past, which is a risk factor of cancers (32). In addition, p53 was also expected to play an important role in cancer treatment with its mutation predicting a substantially worsened prognosis (33). Several retrospective studies have suggested the p53 gene mutation as an adverse prognostic indicator in breast cancer patients. It can predict early recurrence, sensitivity to chemotherapy, and death in breast cancer patients (34).

On the other hand, cyclin D1 is a cell cycle regulator and plays an important role in cell growth. The cyclin-dependent kinases can not regulate cell growth without the cyclin subunit. It is reported that cyclin D1 expression can be regulated by p53 (35). Besides controlling the cell cycle, cyclin D1 was found to be associated with the estrogen receptor (ER) (36). Cyclin D1 can bind to the ER and stimulate its transcriptional activities. The cyclin D1 and ER complex may play a role in stimulating the tumor cell proliferation. The cyclin D1 level can be modulated by changing growth factors in the medium used to culture cells. Cyclin D1 was found to be overexpressed in over $50 \%$ of breast cancer patients and is known as one of the most overexpressed proteins in breast cancer (36).

Our previous data have shown that there are still unknown growth factors which may be secreted by the Z-implanted beef heifers into blood circulation by up-regulating cyclin D1 and down-regulating p53 expression. These unknown growth factors are responsible for stimulatory action in the MCF-7 and primary cultured human normal breast epithelial cells and pre-adipocytes proliferation. 
Our experimental data demonstrated that proliferation of pre-adipocytes isolated from adipose tissues of 60-day Z-implanted beef heifers was about 12 -fold faster than that of the control pre-adipocytes (12). We have also demonstrated that Z-containing sera and meat extracts harvested from the Z-implanted beef heifers (30, 60, 90 days post-Z-implantation) possess potent mitogenic activities in stimulating the proliferation of primary cultured human normal, cancerous breast epithelial cells and MCF-7 cells. $\mathrm{Z}$ at $10 \mathrm{nM}$ induced an 18 -fold increase in aromatase mRNA expression levels in primary cultured human normal breast pre-adipocytes after $24 \mathrm{~h}$ of exposure.

This current experimental data showed that ZS stimulated MCF-10A proliferation more than the NZS. Because the feed environment for these two groups is the same except the $\mathrm{Z}$ implantation, the only difference in MCF- 10A proliferation is due to the $\mathrm{Z}$ implantation in beef heifer. According to this current study, one of the mechanisms of ZS inducing the MCF-10A proliferation is that the ZS can down-regulate p53 and up-regulate cyclin D1 expression subsequently resulting in MCF-10A transformation. Consequently, ZS might play a role in breast neoplasia and breast cancer development.

In summary, ZS significantly stimulates MCF-10A proliferation in a dose-dependent fashion as compared to the NZS. There may be some unknown growth factors in ZS, and ZS appear to increase MCF-10A cell growth by up-regulating cyclin D1 and decreasing p53 expression. Interestingly, MCF-10A acquires the capability of colony formation in soft agar after a 10 -cycle treatment by $1 \% \mathrm{ZS}$, but, not by $1 \%$ NZS The results suggest that $1 \%$ of ZS harvested from 60 -day post $72 \mathrm{mg} \mathrm{Z}$ pellets implanted beef cattle are capable in transforming the human normal breast epithelial cell line, MCF-10A to neoplastic breast cancer cells in 21-day culture. Furthermore, these results implicate the potential risk of consuming beef products with $\mathrm{Z}$ and its metabolites in breast cancer development. Our laboratory is the first to disclose that ZS can facilitate transformation of MCF-10A to neoplastic cells which might be mediated by its up-regulating cyclin D1 and down-regulating p53 expression in the cells. More mechanisms will be studied in the future.

\section{Acknowledgements}

This study was supported by National Institutes of Health, USA (Grant R01 ES 015212).

\section{References}

1. Jemal A, Siegel R, Ward E, Hao Y, Xu J and Thun MJ: Cancer statistics, 2009. CA Cancer J Clin 59: 225-249, 2009.

2. Coe JE, Ishak KG, Ward JM and Ross MJ: Tamoxifen prevents induction of hepatic neoplasia by zeranol, an estrogenic food contaminant. Proc Natl Acad Sci USA 89: 1085-1089, 1992.

3. Massart F, Meucci V, Saggese G and Soldani G: High growth rate of girls with precocious puberty exposed to estrogenic mycotoxins. J Pediatr 152: 690-695, 2008.

4. Takemura H, Shim JY, Sayama K, Tsubura A, Zhu BT and Shimoi K: Characterization of the estrogenic activities of zearalenone and zeranol in vivo and in vitro. J Steroid Biochem Mol Biol 103: 170-177, 2007.

5. Liu S and Lin YC: Transformation of MCF-10A human breast epithelial cells by zeranol and estradiol-17beta. Breast J 10: 514-521, 2004.
6. Yuri T, Tsukamoto R, Miki K, Uehara N, Matsuoka Y and Tsubura A: Biphasic effects of zeranol on the growth of estrogen receptor-positive human breast carcinoma cells. Oncol Rep 16: 1307-1312, 2006.

7. Liu S, Sugimoto Y, Sorio C, Tecchio C and Lin YC: Function analysis of estrogenically regulated protein tyrosine phosphatase gamma (PTPgamma) in human breast cancer cell line MCF-7. Oncogene 23: 1256-1262, 2004.

8. Xu P, Ye W, Jen R, Lin SH, Kuo CT and Lin YC: Mitogenic activity of zeranol in human breast cancer cells is enhanced by leptin and suppressed by gossypol. Anticancer Res 29: 4621-4628, 2009.

9. Swan SH, Liu F, Overstreet JW, Brazil C and Skakkebaek NE: Semen quality of fertile US males in relation to their mothers' beef consumption during pregnancy. Hum Reprod 22: 1497-1502, 2007.

10. Linos E, Willett WC, Cho E, Colditz G and Frazier LA: Red meat consumption during adolescence among premenopausal women and risk of breast cancer. Cancer Epidemiol Biomarkers Prev 17: 2146-2151, 2008.

11. Aw TC, Smith AB, Stephenson RL and Glueck CJ: Occupational exposure to zeranol, an animal growth promoter. Br J Ind Med 46: 341-346, 1989.

12. Ye W, Xu P, Threlfall WR, Jen R, Li H, Lin SH, Kou CT and Lin YC: Zeranol enhances the proliferation of pre-adipocytes in beef heifers. Anticancer Res 29: 5045-5052, 2009.

13. Schmittgen TD and Livak KJ: Analyzing real-time PCR data by the comparative CT method. Nat Protoc 3: 1101-1108, 2008.

14. Ye W, Xu P, Zhong S, Threlfall WR, Frasure C, Feng E, Lin SH, Liu J and Lin YC: Serum harvested from heifer one month postZeranol implantation stimulates MCF-7 breast cancer cell growth. Exp Ther Med (In press).

15. Russo J, Tahin Q, Lareef MH, Hu YF and Russo IH: Neoplastic transformation of human breast epithelial cells by estrogens and chemical carcinogens. Environ Mol Mutagen 39: 254-263, 2002.

16. Ward E, Jemal A, Cokkinides V, et al: Cancer disparities by race/ethnicity and socioeconomic status. CA Cancer J Clin 54: 78-93, 2004.

17. Newman LA: Breast cancer in African-American women. Oncologist 10: 1-14, 2005.

18. McDonald JT and Neily J: Race, immigrant status, and cancer among women in the United States. J Immigr Minor Health, doi:10.1007/s10903-009-9268-1, 2009.

19. Ghumare SS and Cunningham JE: Breast cancer trends in Indian residents and emigrants portend an emerging epidemic for India. Asian Pac J Cancer Prev 8: 507-512, 2007.

20. Andreeva VA, Unger JB and Pentz MA: Breast cancer among immigrants: a systematic review and new research directions. J Immigr Minor Health 9: 307-322, 2007.

21. Kelsey JL and Berkowitz GS: Breast cancer epidemiology. Cancer Res 48: 5615-5623, 1988.

22. Goldin BR, Adlercreutz H, Gorbach SL, et al: The relationship between estrogen levels and diets of Caucasian American and Oriental immigrant women. Am J Clin Nutr 44: 945-953, 1986.

23. Sieri S, Krogh V and Bolelli G, et al: Sex hormone levels, breast cancer risk, and cancer receptor status in postmenopausal women: the ORDET cohort. Cancer Epidemiol Biomarkers Prev 18: 169-176, 2009.

24. Arslan AA, Shore RE, Afanasyeva Y, Koenig KL, Toniolo P and Zeleniuch-Jacquotte A: Circulating estrogen metabolites and risk for breast cancer in premenopausal women. Cancer Epidemiol Biomarkers Prev 18: 2273-2279, 2009.

25. Im A, Vogel VG, Ahrendt G, et al: Urinary estrogen metabolites in women at high risk for breast cancer. Carcinogenesis 30: 1532-1535, 2009.

26. Kabat GC, O'Leary ES, Gammon MD, et al: Estrogen metabolism and breast cancer. Epidemiology 17: 80-88, 2006.

27. Thiebaut AC, Kipnis V, Chang SC, et al: Dietary fat and postmenopausal invasive breast cancer in the National Institutes of Health - AARP Diet and Health Study cohort. J Natl Cancer Inst 99: 451-462, 2007.

28. van Meeuwen JA, Korthagen N, de Jong PC, Piersma AH and van den Berg M: (Anti)estrogenic effects of phytochemicals on human primary mammary fibroblasts, MCF-7 cells and their co-culture. Toxicol Appl Pharmacol 221: 372-383, 2007.

29. Song D, Liu G, Luu-The V, et al: Expression of aromatase and 17beta-hydroxysteroid dehydrogenase types 1,7 and 12 in breast cancer. An immunocytochemical study. J Steroid Biochem Mol Biol 101: 136-144, 2006. 
30. Hartmann A, Blaszyk H, Kovach JS and Sommer SS: The molecular epidemiology of p53 gene mutations in human breast cancer. Trends Genet 13: 27-33, 1997.

31. Toillon RA, Chopin V, Jouy N, Fauquette W, Boilly B and Le Bourhis X: Normal breast epithelial cells induce p53-dependent apoptosis and p53-independent cell cycle arrest of breast cancer cells. Breast Cancer Res Treat 71: 269-280, 2002.

32. Freudenheim JL, Bonner M, Krishnan S, et al: Diet and alcohol consumption in relation to p53 mutations in breast tumors. Carcinogenesis 25: 931-939, 2004.
33. McGill G and Fisher DE: p53 and cancer therapy: a double-edged sword. J Clin Invest 104: 223-225, 1999.

34. Blaszyk H, Hartmann A, Cunningham JM, et al: A prospective trial of midwest breast cancer patients: a p53 gene mutation is the most important predictor of adverse outcome. Int J Cancer 89: 32-38, 2000.

35. Lorincz AM and Sukumar S: Molecular links between obesity and breast cancer. Endocr Relat Cancer 13: 279-292, 2006.

36. Roy PG and Thompson AM: Cyclin D1 and breast cancer. Breast 15: 718-727, 2006. 